\title{
PERFORMANCE CHANGES FOLLOWING CORRECTION OF VISUAL DIFFICULTIES IN GERIATRIC MENTAL HOSPITAL PATIENTS ${ }^{\dagger} \dagger$
}

MARION RUSH STOLL, Ph.D $\ddagger$ and DOROThy COONS

\author{
Division of Gerontology, Institute for Human Adjustment, The University of \\ Michigan, Ann Arbor, Michigan
}

Anyone who is familiar with problems of visual care is aware that the range of accommodation decreases with age so that a time comes, usually in the forties, when the near-point of clear vision has receded to such an extent that near tasks cannot be efficiently or comfortably maintained without the aid of glasses. If cataract develops, increased refractive power of the lens may permit clearer vision at near range without the aid of glasses, substituting a requirement for distance correction to obtain clearer vision for far seeing.

\section{PROGRAM FOR VISUAL CORRECTION}

Examination of geriatric mental patients in a demonstration project $\dagger$ where they were encouraged to join in an activity program revealed that 21 of them had never undergone a refraction examination and 6 of them had worn glasses not preseribed for them. Many others had lost their glasses. Of the 147 who were available for complete examination, 88 appeared likely to achieve significant improvement in acuity with the aid of appropriate correction; that is, nearly 60 per cent appeared to be handicapped by correctable visual deficiencies. Since personal and state funds were limited, the American Optical Company kindly agreed to contribute the prescription corrections needed by these patients. At that time it was judged that significant benefit might be experienced by the use of bifocals for 28 of these patients, of distance corrections for 5 , and of near corrections for 55 who either could see satisfactorily without correction for distance or who rejected the idea of bifocals.

The program of visual correction, it was hoped, would give a measure of the unmet visual needs of such a group and of the extent to which they might demonstrably benefit by provision of corrective glasses. The measure of need was demonstrated and has been reported (1). The measure of benefit proved less capable of determination. Patients' expressions of gratitude sometimes seemed to represent appreciation of the interest shown, rather than recognition of improvement in seeing. Various performance records were obviously related to

* Conclusion of report on the visual status of a group of geriatric mental hospital patients. The first report, "Visual Potential and Its Use in Geriatric Mental Hospital Patients," was published in the Journal of the American Geriatrics Society 11: 472 (May) 1963.

$\dagger$ Research project conducted by the Division of Gerontology of the Institute for Human Adjustment, University of Michigan, with the aid of a grant from the U.S. Office of Vocational Rehabilitation and the cooperation of the Michigan Office of Vocational Rehabilitation and the Ypsilanti State Hospital.

$\ddagger$ Consultant, Brookline Health Department, Brookline, Mass. 
TABLE 1

Distribution of New Prescription Glasses by Type of Correction and Age of Recipients*

\begin{tabular}{|c|c|c|c|c|}
\hline \multirow{2}{*}{ Type of Glasses } & \multicolumn{3}{|c|}{ Age of Patients } & \multirow{2}{*}{ Totals } \\
\hline & $55-64$ & $65-74$ & $75+$ & \\
\hline Bifocals. & 8 & 18 & 10 & 36 \\
\hline Near only. & 8 & 7 & 5 & 20 \\
\hline \multirow[t]{2}{*}{ Distance only $\ldots \ldots \ldots \ldots \ldots$} & 2 & 1 & 3 & 6 \\
\hline & - & - & - & 一 \\
\hline$\ldots \ldots \ldots$ & 18 & 26 & 18 & 62 \\
\hline
\end{tabular}

* Chi squared, calculated for bifocals versus single vision, was 2.69 . Not significant.

other uncontrollable variables or were not closely related in time to the experience of receiving the glasses.

Patients were constantly being discharged or moved to other facilities in accordance with Michigan's statutory requirements. Between the time of first examination and completion of frame measurements for the individual prescriptions, so many patients had become unavailable that even with the addition of a few who had not been included in the original 88 deemed likely to benefit in terms of the original criteria, only 62 prescriptions were completed and filled. These were distributed in respect to age and type of correction as shown in Table 1. Thirty-six patients received bifocals, 20 received corrections for near vision only, and 6 received corrections designed chiefly to improve distance vision.

These glasses were prescribed according to the indicated needs; no significant differences in respect to age distribution resulted. Comparison with the earlier data concerning unmet needs emphasizes the fact that bifocals were prescribed more frequently than seemed to be demanded in order to meet criteria of significant potential improvement; distance corrections were also prescribed for some who were not aware of a loss in distance seeing or who could not achieve 20/200 with correction. Decisions to prescribe such corrections were made possible by the kindness of the contributor and were motivated by experience acquired during an emergency measure designed to enable some patients to function more efficiently in a new sheltered-workshop job.

\section{WORK GLASSES-AN EMERGENCY MEASURE}

Before we had any assurance that the desired prescription glasses could be provided, a more demanding task - visually demanding - was offered to the sheltered workshop by a cooperating industrial concern. Many patients greeted the new job with enthusiasm but soon complained that the nuts and screws were too small. Review of data from the visual examinations indicated that 14 of those who wanted to work obviously required glasses if they were to succeed in this near-vision task. The importance of demonstrating their capacity in this industrial job dictated a possible solution, i.e., the patients could be supplied with "reading glasses" available in a local store. These are identical spherical 
plus-lenses for the two eyes and are provided in a range of powers and of frame sizes. From the examiner's point of view the decision to use this resource represented an appalling choice but the need was urgent.

Fortunately, examination of the records of these 14 patients showed that 9 men who were eager to work represented a self-selected group with minimal refractive errors. Two of the 9 were slightly myopic; several could benefit by a mild plus-correction for distance; none had any significant amount of astigmatism. A tenth man showed a marked refractive difference between his two eyes-one eye was near-sighted and the other was far-sighted. All of these men could see fairly well for distance and several had rejected the suggestion of glasses when first examined. The essential needs of the first 9 could be satisfied reasonably well by a selection from the available "reading glasses," made by the examiner on the basis of the examination data. The tenth man and the 4 women showed greater differences between their two eyes or greater measures of astigmatism. One of the women, who had lost her glasses and could see only 20/200 for distance without correction, was provided with a strong pair of plus-lenses which represented a correction intermediate between her requirements for distant and for near vision. She literally danced with excitement, crying, "I can see! I can see!" The other women and the tenth man were also provided with the available "reading glasses" to avoid their being left out; however, as predicted, they soon rejected them as affording little help. The staff worker who distributed the glasses reported that several patients were amazed to discover the difference in their seeing. The whole atmosphere of the workshop changed. Now patients could see to do the new work, and they were pleased to be busy with an industrial task. They surprised both the staff and the cooperating industrialists by demonstrating both enthusiasm and efficiency.

\section{PRESCRIPTION GLASSES}

The new prescribed correction glasses for 62 patients in the experimental and control groups were received just at Christmas time and were greeted as a welcome and magnificent present. We hoped to secure information about the patients' responses during the concluding months of the program and to evaluate the enduring importance to them of this opportunity to enjoy better vision. Adequate data could be secured only on patients who remained at the hospital in the experimental ward. Mrs. Coons, Director of Industrial Therapy, provided observations on the patients' use of their glasses, indications of appreciation, and the work activities of the $\mathbf{4 0}$ patients in her group.

Twenty-nine of these 40 wore their glasses about as they were designed to be used, including 6 patients who were so confused that their glasses were frequently mislaid. One of these 6 indicated his recognition of the importance of the glasses by picking up those belonging to other patients when he could not locate his own. Another wore an elastic band to keep his glasses always in place and thus avoid losing them; he elected to wear them constantly although they were designed only for near work. Table 2 presents data on the use of their corrective glasses by this group of 40 patients, with information on age distri- 
TABLE 2

Response to Corrective Glasses by 40 Patients in the Activity Program, Distributed by Age and Types of Correction*

\begin{tabular}{|c|c|c|c|c|}
\hline \multirow{2}{*}{ Response } & \multicolumn{3}{|c|}{ Age of Patients } & \multirow{2}{*}{ Totals } \\
\hline & $55-64$ & $65-74$ & $75+$ & \\
\hline Glasses worn regularly........ & 10 & 11 & 8 & 29 \\
\hline Bifocals . . . . . . . . . . . . & 6 & 8 & 5 & 19 \\
\hline Near only . . . . . . . . . . . . & 3 & 2 & & 5 \\
\hline Distance only . . . . . . . . & 1 & 1 & 3 & 5 \\
\hline Glasses rejected $\ldots \ldots \ldots \ldots \ldots$ & 3 & 2 & & 5 \\
\hline Bifocals . . . . . . . . . . & & 2 & & 2 \\
\hline Near only . . . . . . . . . . . & 2 & & & 2 \\
\hline Distance only ............ & 1 & & & 1 \\
\hline Glasses lost $\ldots \ldots \ldots \ldots \ldots \ldots$ & 1 & 4 & 1 & 6 \\
\hline Bifocals . . . . . . . . . . & & 2 & & 2 \\
\hline Near only . . . . . . . . . . . & 1 & 2 & 1 & 4 \\
\hline
\end{tabular}

* No statistically significant differences shown.

bution and type of corrections provided. Twenty-nine wore the glasses regularly; 5 rejected them; 6 lost them or reported them stolen. The group was too small to yield statistically significant differences in respect to age grouping. Classification of glasses as 1) bifocals or single vision and 2) worn regularly or not worn, also yielded no statistically significant differences.

It is noteworthy that the patients aged 75 and over were as ready as younger patients to adapt to the glasses and to wear them constantly. Glasses for distance correction only were more frequently provided for patients aged 75 or older-an age when the incidence of cataract increases. Two men required such strong myopic corrections for distance that partial correction only seemed advisable; their glasses improved acuity for near vision as well as for distance vision, and both patients wore them constantly. Three others whose corrections were suitable only for distance vision wore their glasses as intended, but 1 rejected hers as unnecessary. Two patients rejected glasses designed for near vision; 4 others mislaid theirs; but 5 wore them regularly. Bifocals were rejected by 2 patients; 2 others lost theirs; but 19 wore them regularly. These differences, although not statistically significant, indicate the advantages to these patients of being able to wear their corrective glasses constantly. Most of these patients are confused, at least at times, and trying to keep track of glasses (even with various aids to prevent mislaying them) presents too much of a problem unless they are worn constantly. Those who were less confused usually indicated appreciation of improved acuity and took measures to assure retention of this gain by being very careful with their glasses. This was true of 2 patients who had been provided with bifocals but preferred to wear them only for near work. 
TABLE 3

Mental Status Quotients Indicating Gains, No Change and Losses Among 40 Patients Who Either Did or Did Not Wear Their New Prescription Glasses.

(Distribution by Age)*

\begin{tabular}{|c|c|c|c|c|}
\hline & \multicolumn{3}{|c|}{ Age of Patients } & \multirow{2}{*}{ Totals } \\
\hline & $55-64$ & $65-74$ & $75+$ & \\
\hline Wearing corrections. ......... & 10 & 11 & 8 & 29 \\
\hline Gain in mental status....... & 5 & 7 & 4 & 16 \\
\hline No change $\ldots \ldots \ldots \ldots \ldots$ & 3 & 1 & 3 & 7 \\
\hline Loss . . . . . . . . . . . & 1 & 2 & 1 & 4 \\
\hline Data incomplete .......... & 1 & 1 & & 2 \\
\hline Glasses rejected or lost....... & 4 & 6 & 1 & 11 \\
\hline Gain in mental status....... & 3 & & & 3 \\
\hline No change $\ldots \ldots \ldots \ldots \ldots$ & 1 & 2 & 1 & 4 \\
\hline Loss. . . . . . . . . . . . . & & 2 & & 2 \\
\hline Data incomplete.......... & & 2 & & 2 \\
\hline
\end{tabular}

* No statistically significant differences shown.

\section{MENTAL STATUS QUOTIENTS}

Measures of the mental status of each patient in the total project were designed to be determined at the beginning and near the end of the program. Details of procedures and the conclusions have been reported by Dr. Gottesman, the Project Director (2). Measurements were derived from evaluations of individual responses to a questionnaire which was a modification of the Goldfarb Mental Status Questionnaire (3). Measures ranged from 0 to 13 but a high proportion were rated the same on the two occasions.

Among the 40 patients for whom Mrs. Coons' observations were reported, the range of mental status quotients extended from 2 to 13 ; a few of the subjects showed marked changes; data for 4 were incomplete.

Table 3 indicates the distribution of the two relative measures of mental status for the 29 patients who wore their glasses regularly and the 11 who lost them or rejected them. Again, numbers were too few to permit valid analysis of age differences, but when the data were grouped to yield a simple four-fold table (Table 4), the distribution indicated some association between improvement in mental status and the wearing of new glasses. The data do not support any expectation that such association can be anticipated with confidence, but they suggest that those who are ready to accept the responsibilities of improved visual acuity may also show improvement in other respects.

The total group of patients examined for visual difficulties included many who were already wearing acceptable corrective glasses. When these are included among those for whom glasses were provided here, more marked differences appeared between the group wearing glasses and the group for whom none were ordered. Data concerning mental status quotients were incomplete for 54 of the 154 patients who underwent refraction examinations. This left 100 for whom 
TABLE 4

Association between Use or Non-use of Newly Prescribed Glasses and Gain or Lack of Gain in Mental Status Quotients in 36 Patients for Whom Complete Data were Available*

\begin{tabular}{|c|c|c|c|}
\hline Mental Status Quotients & Gain & No Gain & Totals \\
\hline Glasses used........... & 16 & 11 & 27 \\
\hline Glasses not used ......... & 3 & 6 & 9 \\
\hline & 一 & - & 一 \\
\hline Totals. & 19 & 17 & 36 \\
\hline
\end{tabular}

* No statistically significant differences shown.

TABLE 5

Mental Status Quotients in Terms of Gain, No Change or Loss Between the First and Second Examinations in Association with Use of Glasses, as Noted at the Time of Refraction or after Provision of Needed Correction*

\begin{tabular}{|c|c|c|c|c|}
\hline Mental Status Quotients & Gain & No Change & Loss & Totals \\
\hline Wearing corrective glasses when admitted. & 10 & 12 & 13 & 35 \\
\hline Glasses provided here. & 22 & 15 & 12 & 49 \\
\hline No glasses; none prescribed. & $2 \dagger$ & 7 & 7 & 16 \\
\hline & - & - & - & - \\
\hline Totals. & 34 & 34 & 32 & 100 \\
\hline
\end{tabular}

* No statistically significant differenees shown.

$\dagger$ These 2 patients were classified as blind; one had no light perception; the second had only light perception.

data concerning the wearing of glasses could be correlated with results of mental status examinations (Table 5). Again no statistically significant differences are apparent, but gains were greater among those wearing corrective glasses, and were especially frequent among those whose visual status was improved by the provision of needed glasses. Those who wore no glasses and for whom none were provided included some patients who were unable to cooperate for adequate examination and some whose vision could not be improved by correction. Two in this group were classified as blind; they were the only ones who showed a gain in mental status. It may be that those who had lost their glasses and were eager to have new ones were manifesting an improved mental status which was subsequently confirmed by measurement. That possibility and other variablesa positive response to the therapeutic program or, conversely, mental and physical deterioration-made it futile to pursue an effort to determine just what the glasses may have contributed to the rehabilitation or general improvement of this selected group of subjects.

\section{SUMMARY AND CONCLUSIONS}

Refractive examination of 154 geriatric mental hospital patients indicated that more than 50 per cent might benefit from provision of visual corrections 
since many had lost their glasses in the course of illness and others had never had corrections prescribed.

The needs of these patients were emphasized when they were given an opportunity to participate in an industrial workshop project which required good near vision.

Provision of prescribed corrections was greatly appreciated by many of these patients and even those aged 75 or older often began to wear the glasses constantly.

Bifocals were more regularly worn than single-correction glasses because they were less likely to be mislaid. Two patients (aged 75 and 77) constantly wore strong, single-vision, myopic corrective glasses that improved acuity for near as well as for distance vision.

Too many significant variables were involved to permit measured evaluations of the part played by provision of new glasses in the favorable directions of mental change reported for some patients, but many depended upon the glasses for more efficient performance in the workshop and at other tasks.

The impression that provision of needed glasses may have been an element in the improvement of mental status in some of these aged patients could not be clearly demonstrated, but the data tend to support the expectation that improved visual efficiency may have a significant effect in many cases.

\section{REFERENCES}

1. Stoll, M. R.: Visual potential and its use in geriatric mental hospital patients, $J$. $A m$. Geriatrics Soc. 11: 472-484, 1963.

2. GotTesman, L., And Schneider, P.: The interactions of opportunity, mental status and attitudes in rehabilitation of the geriatric mentally ill. Presented at the 6th International Congress of Gerontology, Copenhagen, Denmark, 1963.

Gottesman, L. E. : Problems in assessing determinants of normal and pathological aging. Paper given at the American Psychological Association meetings. St. Louis, 1962.

Gotresman, L. E.: Place of the institution in the care of the chronically ill geriatric patient. Paper given at the Rehabilitation Conference, John Kane Hospital, Pittsburgh, Pa., 1962.

3. KaHn, R. L.; Goldfarb, A. I.; Pollack, M., and Gerber, I. E.: The relationship between mental and physical status in institutionalized aged persons, Am. J. Psychiat. 117: 120-124, 1960. 